\title{
Integrated Reporting and Italian Companies: An Empirical Investigation
}

\author{
Guido Paolucci ${ }^{1} \&$ Eva Cerioni ${ }^{1}$ \\ ${ }^{1}$ Department of Management, Università Politecnica delle Marche, Ancona, Italy \\ Correspondence: Eva Cerioni, Department of Management, Università Politecnica delle Marche, Piazzale \\ Martelli, 8-60121 - Ancona, Italy. E-mail: e.cerioni@pm.univpm.it
}

Received: July 3, 2017

Accepted: August 8, 2017

Online Published: August 12, 2017

doi:10.5539/ijbm.v12n9p221

URL: https://doi.org/10.5539/ijbm.v12n9p221

\begin{abstract}
Corporate reporting has undergone many changes. One main reason is that stakeholders see their needs change and evolve, thus making it necessary for them to express their various requests for information which, in turn, force companies to rethink their external reporting practices. Recent studies support the position that the traditional annual report does not provide stakeholders with an adequate picture of the assets and the value created by the company. In response to this, Integrated Reporting (IR) has been adopted as a solution capable of providing both a holistic view of a company's ability to create value in a sustainable way and an integrated vision of the company from a financial and a non-financial point of view. Thus, this paper aims to examine the real reasons that have pushed major Italian companies to opt for IR and, especially, to explore the benefits that can now be identified a few years beyond the first publication of an Integrated Report. To investigate this topic, an exploratory field study involving eleven Italian companies was conducted. The methodology relied on a qualitative approach, as it allows researchers to deal with complex "how" questions and, at the same time, offers a wide and complete picture of the phenomenon. The paper gives senior managers an overview of Italian companies that have already developed this new form of information reporting, while providing valuable insights and an understanding of the perceived organizational benefits of implementing IR requirements. The study also contributes to the debate on managerial motives for producing an Integrated Report and how that may affect future decisions. The findings reveal a common thread among all the study participants, summarized by the completeness and transparency of the results. They also highlight an exhaustive list of benefits reported by these companies, which may serve as an incentive for those that have not yet adopted IR.
\end{abstract}

Keywords: Integrated Reporting, motivations, benefits, critical issues, non-financial information

\section{Introduction}

The world of corporate reporting is undergoing many changes. Noteworthy are the qualitative and quantitative data that companies are required to control and report. Integrated Reporting (IR) is the new corporate reporting tool that focuses on the ability to create business value by combining and integrating the information contained in single reports (Eccles and Krzus, 2010). Increasingly real and tangible is the need on the part of stakeholders and companies not to have disjointed tools for measuring and reporting performance, albeit containing both financial and non-financial indicators, but a report that shows the influence of the various dimensions of enterprise performance and the manner in which the interaction between the financial and non-financial resources can create value (Neely, 1999; Yongvanich \& Guthrie, 2006; Abeysekera, 2013; De Villiers, Rinaldi, Unerman, 2014). In 2014 the International Integrated Reporting Council (IIRC) published the IR framework, to give a general guideline to companies wishing to adopt this new instrument of Integrated Reporting. This work aims to identify how the major Italian companies start down the path to Integrated Reporting and what the prevailing motivations are that might drive companies to adopt this reporting tool. Top management needs real motivations for and certainties concerning the benefits of adopting a new tool for reporting the company's performance. This work was carried out using a qualitative methodology, field study, which, through the use of semi-structured interviews, allowed the authors to collect data from major Italian companies that have already used the IR approach. The main objective of the work is to examine the main reasons that prompted the top managers of these companies to draw up the IR as well as the related benefits, in order to generalize the results and contribute to the literature concerning this aspect. 


\section{Theoretical Background}

The term "integrated" was first mentioned by Allen White (2005) in his discussion of Novo Nordisk's company report which he termed an example of "integrated, balanced, and candid reporting", published in Business for Social Responsibility titled "New Wine, New Bottles: The Rise of Non-Financial Reporting". In 2010 Eccles defined reporting as "the process of ESG integration into the annual report of companies" (Eccles \& Krzus, 2010). According to the International Integrated Reporting Council (IIRC), Integrated Reporting contains material information about an organization's strategy, governance, performance, and future prospects which reflect the economic, social, and environmental context where the company operates. The International Integrated Reporting Council (IIRC) was constituted on August 2, 2010 by "The Prince's Accounting for Sustainability Project" (A4S) and the "Global Reporting Initiative" (GRI). The main objective of the IIRC is to create a globally accepted framework for Integrated Reporting. The aim of this framework consists in bringing together financial, environmental, social, and governance information in a clear, concise, consistent, and comparable format (International Integrated Reporting Council, 2013). Integrated Reporting is a process that enables an organization to externally communicate cumulative information on creating value over time, thereby meeting the requirements of transparency and reliability of the market (Krzus, 2011; Eccles \& Serafeim, 2015). IR is not simply a new reporting tool, but a new theory of enterprise (concepts of capitals, new concept of performance, innovative metrics, holistic/systemic vision, procedural approach, etc). In the first instance it can be identified as a mere aggregate of economic-financial reporting and a sustainability report, when in fact it is much more (Stubbs \& Higgins, 2014). The International Integrated Reporting Council (IIRC) tells us that the aim of the IR is to explain the process of creating business value through the representation of "combinations, correlations, and dependencies among the relevant factors that affect the organization's ability to create value over time" (IIRC, 2013, p. 16). Eccles argues that making a "One Report" means producing a single report that combines information and financial narration with information and non-financial narration, so with the environmental, social, and governance issues (Eccles \& Krzus, 2010). By "One Report" we may refer to either a single document where the company provides a holistic view of the interests of all its stakeholders, or a comprehensive report of financial and non-financial information that shows the impact of both (Vergnano, 2010). Globally, in 2010, the IIRC argued that for the purposes of Integrated Reporting it is undoubtedly necessary to create a globally-accepted framework for reporting on the organization, a framework that brings together financial, environmental, social, and governance reporting in a clear, concise, consistent, and comparable format, a more retrospective and prospective model, that aims to meet the needs of an economic model more sustainably and more globally. In December 2013 the IIRC published the international Framework of Integrated Reporting. IIRC shows that the Integrated Report is a form of reporting which differs from others because it focuses on an organization's capacity to create value in the short, medium, and long term and especially, because it manages to do so in a concise manner, with a strategic focus, and having as a base the consideration that all information and capital of the enterprise are connected and influence each other (IIRC, 2013). The company must undertake a managerial revolution (Busco, Frigo, Quattrone, \& Riccaboni, 2013; Thomson, 2015; Stubbs \& Higgins, 2014) before being able to draw up an IR.

An Integrated Report is a summary communication that shows how the strategy, governance, performance, and prospects of an organization, in the external context in which it operates, allow the creation of value in the short, medium, and long term (Cheng, Green, Conradie, Konishi, \& Romi, 2014). The IR aims to promote a more coherent and efficient approach to design both the reporting of performance and the management of the enterprise (Stubbs \& Higgins, 2014; Adams, 2014). The IR proposes a model which has the ultimate purpose of explaining how the dimensions of performance interact with each other (Abeysekera, 2013; Van Bommel, 2014; Thomson, 2015). The IR is intended to communicate how the company works and how activities affect the resources invested, both financial and non-financial. To do this, however, appropriate metrics for sustainability and intangibles are needed, so as to link them to value creation (viewed as a whole, and not only from a financial point of view) using the principle of connectivity and Integrated Thinking (IIRC, 2013; Hampton, 2012).

The use of IR by the company implies a new approach to business management and creation of value, oriented to "Integrated Thinking \& Action". Companies should be able to obtain and manage the information they need in relation to intangible components; this involves a restructuring of the company's internal measurement and reporting systems to produce a single Integrated Report (Stubbs \& Higgins, 2014; South Africa Institute of Chartered Accountants, 2015). The company that manages to produce an Integrated Report requires a new framework which provides constant inter-functional cooperation, based on a growing culture of cross-reporting and attention towards all stakeholders. A company should be considered a single entity that works to achieve strategic objectives (King and Roberts, 2013); only with the integrated thinking the company has the ability to 
see resource connections and relationships between different functions, between departments, and between business operations (King and Roberts, 2013). With integrated reporting, the whole organizational culture of the company changes, something that has not happened with any of the other reporting tools.

IR shows the influence of the various dimensions of performance and the manner in which the interaction between financial and non-financial resources is able to create value (Abeysekera, 2013; De Villiers et al, 2014; Mohammad, 2017).

This tool enables all types of reporting features to co-exist within Integrated Reporting (Morros, 2016). For this reason, IR is not merely a business reporting tool, but it extends beyond reporting (Steyn, 2014). There is no doubt that Integrated Reporting is a prominent tool for business organization (Churet \& Eccles, 2014; Havlová, 2015).

The aim of IIRC is that the IR will become a mandatory reporting tool by 2020. Taking a look at Italy, among the first large companies that have already implemented an Integrated Report there are Eni S.p.A., Enel S.p.A., Generali S.p.A., Aspiag Service S.r.l. - DESPAR Nordest, Terna S.p.A., Atlantia S.p.A., A2A S.p.A., and UniCredit S.p.A. In this study we analyze the path followed by these major Italian companies as they have moved towards implementation of Integrated Reporting.

\section{Benefits}

The benefits gained from Integrated Reporting will not only be for the companies producing the report, but also for their stakeholders. Investors are the main beneficiaries of the potentialities of the Integrated Report, thanks to the quality and amount of information they can glean. Their role in investing on behalf of others will involve fewer risks and responsibilities if their choices are more aware and supported by a full knowledge of the company's performance. Thanks to the Integrated Report, investors are now able to finally have both financial and non-financial information contained within a single document and in an integrated manner, to show how the company creates value over time.

The study "The value of extra-financial disclosure" delves into this aspect and analyzes how 34 investors and 35 analysts use and are affected by non-financial information. The study shows there is broad consensus in saying that IR contributes to increase the usefulness of extra-financial information through improved reliability, accessibility, relevance, and comparability of information. According to the study, about one-third or more of investors and analysts have said that Integrated Reporting will be very helpful, not only in terms of the many benefits to be gained therefrom, but also to demonstrate the relevance of non-financial performance on overall performance. The regulators and the definers of standards and policies believe that Integrated Reporting will allow the harmonization of approaches, a reduction of bureaucracy, and greater economic and market stability. Integrated Reporting will take benefits not only to the highest levels of a company but also to all its employees. The latter will have a perspective on the future of the company and will feel connected to the organization by having an understanding of how their performance is linked to the objectives of the enterprise, and then, of how they can contribute to the creation of business value.

Lastly, recent studies (Black Sun, 2012; Blesener, 2014; Ernst \& Young; 2015; Chartered Institute of Management Accountants, 2015) have summarized in a few points the major benefits brought by IR to companies that adopt it. According to these studies Integrated Reporting:

- Increases the company's ability to identify and assess risks;

- Improves decision making because it integrates ESG (Environment, Social, Governance) variables;

- Allows business strategies to be evaluated and compared with those of other companies in the sector;

- Provides data on expected results in the future and facilitates the evaluation of business strategies;

- Offers a comprehensive, concise, and material overview;

- Facilitates access to credit and capital markets;

- Improves the quality of governance, since the IR approach is adopted and guided by the managers who have decision-making power;

- Improves the organization's image by referring to future objectives;

- Improves the relationships with stakeholders;

- Improves inter-departmental connections. 
Now, we asked ourselves: "What is actually going on in Italy?", "What are the benefits that major Italian companies are experiencing with the adoption of the Integrated Report?", and above all, "What are the reasons underlying their choice to undertake Integrated Reporting?"

\section{Research Method}

With the aim of answering the research questions, the authors of this paper conducted an exploratory study (Kaplan, 1986; Roslender and Hart, 2003; Lillis and Mundy, 2005), involving Italian companies that are members of the IIRC Business Network and other companies that have distinguished themselves for having adopted Integrated Reporting. The research method used is the field study. It is a qualitative research method involving "limited-depth studies conducted at a non-random selection of field sites, thus lying somewhere between in-depth cases and broad-based surveys" (Lillis and Mundy, 2005, p. 120). The field study method is one that gives a broad and complete view of the phenomenon and allows researchers to collect ideas on the relevance of it (Roslender and Hart, 2003). Moreover, when collecting data from surveys it is a much less structured method and, indeed, less intensive and thorough than a case study (Lillis and Mundy, 2005).

The aim of the research was to provide a complete overview of Italian companies involved in the Integrated Reporting. Through the field study method, it was possible to apply a not-too-thorough analysis to more units of study than those imposed by the multiple case study method (Lillis and Mundy, 2005). For this reason, the idea of conducting a multiple case study was discarded. Before deciding to adopt the field study method, the authors also assessed the possibility of adopting the survey method, so as to provide a general understanding of the phenomenon. However, this was discarded too; given the fact that the few surveys that have been conducted were mostly on the motivations that drive companies to choose Integrated Reporting, it was deemed problematic and inappropriate to submit a questionnaire with specific and closed questions focusing on motivations.

This work is based on evidence gathered from eleven Italian companies (five of which are part of the IIRC Business Network) operating in different sectors (Table1).

Table 1 - Sample companies

\begin{tabular}{l}
\hline Aspiag Service S.r.l.- DESPAR Nordest \\
\hline A2A S.p.A. \\
*Atlantia S.p.A. \\
Banca Fideuram S.p.A. \\
*Consiglio Nazionale dei Dottori Commercialisti ed Esperti Contabili (CNDCEC) \\
Dellas S.p.A. \\
*Enel S.p.A. \\
Eni S.p.A. \\
Generali S.p.A. \\
PricewaterhouseCoopers Advisory \\
Sabaf S.p.A. \\
SNAM S.p.A. \\
Terna S.p.A. \\
UniCredit S.p.A \\
* Did not participate in the project.
\end{tabular}

To build a list of possible candidates, we first identified the Italian companies that were part of the IIRC Business Network in 2016. They are: Atlantia S.p.A, CNDCEC, Enel S.p.A., Eni S.p.A., Generali S.p.A., PricewaterhouseCoopers Advisory, SNAM S.p.A., and Terna S.p.A. The other six companies included in the list are leading Italian companies which, although not part of the IIRC Business Network, have adopted IR and have followed the guidelines of IIRC's International IR Framework. Starting from the initial list of fourteen candidates that was compiled, we proceeded to contact each company by e-mail, to explain the objective of the research project and to determine whether they were interested in the project. Among the eight companies that were part of the IIRC Business Network, these five companies agreed to participate in the research: Eni S.p.A, Generali Group, PricewaterhouseCoopers Advisory, SNAM S.p.A., and Terna S.p.A. The remaining three, 
Atlantia S.p.A., CNDCEC, and Enel S.p.A., declined our request. The final sample of eleven companies that agreed to participate was composed of: A2A S.p.A., Eni S.p.A., Generali S.p.A., PricewaterhouseCoopers Advisory, SNAM S.p.A., Terna S.p.A, Banca Fideuram S.p.A, Dellas S.p.A, Sabaf S.p.A., Aspiag Service S.r.l.-DESPAR Nordest, and UniCredit S.p.A.

To collect the data, semi-structured interviews (Kreiner and Mouritsen, 2005; Qu and Dumay, 2011) were used. This technique allows the interviewer to probe for more information and solicit clarification of answers. Furthermore, although a list of questions to be submitted to the respondent is prepared in advance, "the interview takes place in a colloquial way that offers participants the opportunity to explore the issues they believe are important" (Wengraf, 2001, p. 103). The respondents are managers working in the areas of sustainability, administration, or finance and, in any case, they are very closely involved in the drafting of the company's IR. Those managers were interviewed via Skype and phone. The interviews were conducted from April 2016 to May 2017 and lasted an average of 45 minutes each. They were recorded and later transcribed for analysis. The interviews were divided into five segments of varying length (Roslender and Hart, 2003). The respondents were interviewed on why their companies had decided to draw up an Integrated Report, on the organizational changes needed for the drafting of this new reporting document, on the necessary steps to be taken to implement the IR project, on the difficulties encountered along the way, and finally, on the perceived benefits of Integrated Reporting. Once the interview was transcribed, it was checked by the respondent in order to ensure the accuracy of the data collected. Finally, when all of the interviews had been completed, the next step was the processing and analysis of the data gathered. The objective of our study is to identify how the sample of major Italian companies undertakes the path towards Integrated Reporting and to highlight the motivations, the critical issues, and the benefits - in terms of value creation - connected with the preparation of an Integrated Report.

\section{Findings and Discussion}

Four main points emerged from the interviews: steps, motivations, benefits, and difficulties. Firstly, the companies that have decided to adopt the IR process must follow several steps because it was necessary to instill a new mindset in the company. All of the sample companies stated that before they could implement the Integrated Reporting process, they needed to identify a specific new team, the IR team, composed of several managers representing all the corporate divisions. Therefore, adoption of Integrated Reporting requires that all business areas are involved and interact with each other.

Secondly, concerning the motivations underlying the choice to adopt an IR approach reporting company performance, several key points emerged from the answers given by those who must deal with this new reporting tool on a daily basis. It was reported (by the majority of the interviewees) that the company decided to adopt the Integrated Report because it wanted to simplify and integrate the information regarding its business, trying to highlight its strengths, but mainly trying to represent - to the outside world - its value creation procedure in a comprehensive and transparent way. Through the IR the company presents itself comprehensively and gives value to all of its most strategic tangible and intangible assets. This is the general motivation that can be deduced from the sample analyzed. Indeed, the main motivation that emerges from the sample companies corresponds to market requirements regarding the need for an increasing amount of information that is not only financial and, more importantly, is able to communicate how the company can create value in the present and in the future; the objective of the IIRC to integrate information and to represent the value created by the company enters the business logic and manifests itself both internally and externally through the publication of the IR document.

The third point concerns the benefits that the surveyed companies claim to have achieved thanks to the drafting and implementation of the IR. We classified the emerging benefits into the five categories already present in the literature (ACCA, 2017). The five categories of benefits are:

1. More integrated thinking and management

2. Greater clarity on business issues and performance

3. Improved corporate reputation and relationships with stakeholders

4. More efficient reporting

5. Employee engagement

We represent the different allocation of benefits in the five categories illustrated in Table 2 below. 
Table 2. Categories of benefits

\begin{tabular}{|c|c|}
\hline \multicolumn{2}{|l|}{ More integrated thinking and management } \\
\hline Better allocation of resources & $36 \%$ \\
\hline Better information management and decision making & $91 \%$ \\
\hline Improved quality of management & $9 \%$ \\
\hline Management Control reporting culture created & $64 \%$ \\
\hline \multicolumn{2}{|l|}{ Greater clarity on business issues and performance } \\
\hline Better understanding of how to create value & $100 \%$ \\
\hline Better quality of accounted data and indicators employed & $91 \%$ \\
\hline Simple, concise and inductive performance tracking & $100 \%$ \\
\hline It facilitates unilateral valuation results of the players expected in the future & $100 \%$ \\
\hline Greater relevance to extra-financial performance on the overall performance & $100 \%$ \\
\hline \multicolumn{2}{|l|}{ Improved corporate reputation and stakeholders' relationships } \\
\hline Greater involvement of stakeholders & $64 \%$ \\
\hline More evaluation elements for every stakeholder & $91 \%$ \\
\hline Decrease reputational risk & $73 \%$ \\
\hline Improved understanding of risks and opportunities & $100 \%$ \\
\hline Greater ease of access to credit & $18 \%$ \\
\hline Improved relationship with financial analysts & $73 \%$ \\
\hline Improved relationship with institutional investors & $91 \%$ \\
\hline \multicolumn{2}{|l|}{ More efficient reporting } \\
\hline Representation of the business model adopted & $100 \%$ \\
\hline Opportunity to highlight different operating efficiency measurement & $91 \%$ \\
\hline Ability to identify intervention priorities & $45 \%$ \\
\hline Ability to identify Company's objectives and monitor the progress on projects & $36 \%$ \\
\hline Possibility of offering a complete vision, concise and material & $100 \%$ \\
\hline Increased utility of additional financial information & $100 \%$ \\
\hline Improve image, visibility and reputation of the organization & $73 \%$ \\
\hline \multicolumn{2}{|l|}{ Employees engagement } \\
\hline Increased collaboration and better relationship between the various departments & $91 \%$ \\
\hline
\end{tabular}

The results are summarized in Figure 1, below.

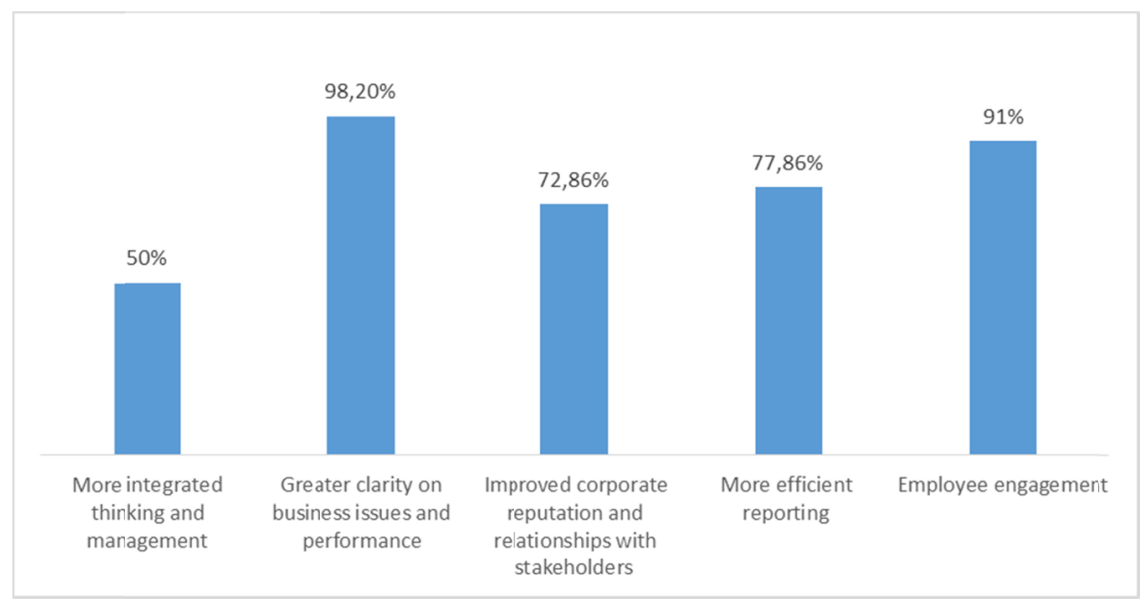

Figure 1. Benefits

Among the companies surveyed, $36 \%$ stated that thanks to the IR they have improved their ability to allocate the resources available. The benefits of improved quality of data reported and indicators used along with the increased collaboration of the departments of the company have emerged from the interview for $91 \%$ of the companies. The $64 \%$ of the companies, however, declared that the IR increases stakeholders' involvement in the company, decreases the reputational risk and improves the company's image. Half of the companies surveyed argued that with the editing of the IR, the company is able to identify priority actions. Only $64 \%$ of companies 
think the IR contributes to the work of management control. In connection with the relationship with financial analysts, the $91 \%$ of the companies argued that such relationship improves thanks to the spread of IR as additional document of company valuation. Finally, with regard to the facilitation of access to credit through the IR, only $18 \%$ said they have had any benefits in this regard. This reflects the fact that for now, the IR is not a tool for reporting mainly considered by the banking sector, since the financial information of the traditional financial statements for this sector remain of utmost importance. Compared to the existing literature, two new benefits emerge from the sample examined: greater appreciation of the company by direct customers and more information available to management in order to make decisions on operations.

The fourth point concerns the difficulties encountered in the process. If the reasons for adopting Integrated Reporting, as given by companies that prepare an IR, seem imminently clear, what is less evident is the amount of the difficulties that these companies have had to deal with before they could publish this new Integrated Reporting tool. Figure 2, below, summarizes the findings in this category.

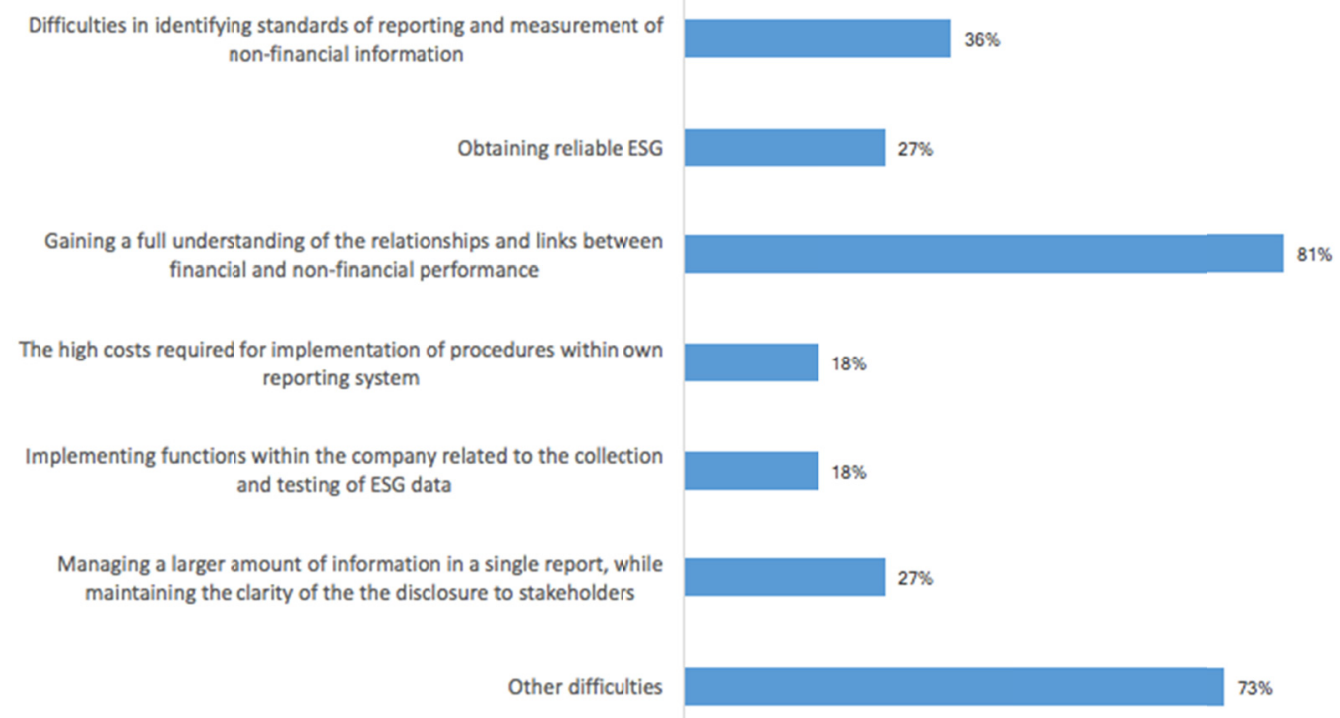

Figure 2. Difficulties

The analysis confirms what has emerged from the literature concerning the difficulties faced by Italian companies in trying to fully understand the relationships and links between financial and non-financial performance, as this difficulty was cited by $81 \%$ of the companies of the sample. In addition, the difficulties in identifying standards of reporting and measurement of non financial information were cited by $36 \%$ of the companies. These difficulties will be overcome only when integrated thinking will be fully rooted in the company. However, $27 \%$ of the companies declare that in compiling the Integrated Report they have had difficulties identifying reliable ESG information and managing a larger amount of information in a single report, while still maintaining the clarity of the disclosure to stakeholders. The other difficulties that are mentioned in the literature appear with the same percentage (18\%) and these are also the ones that are not felt particularly strong by the interviewees. Differently from what is found in literature, from this study also emerged the following types of difficulty: understanding the relationships between the six types of capital highlighted in the framework (financial, manufactured, intellectual, human, social and relationship, natural), spreading the culture of the Integrated Report in all functional areas of the company, comparing the data and getting the message across that the IR is not just a marketing document but much more than that.

\section{Conclusion}

The objective of this paper is to identify how leading Italian companies undertook the path of Integrated Reporting and to shed light on the steps, motivations, critical issues (difficulties) and benefits (in terms of value creation) associated with the preparation of an Integrated Report. This study shows that companies who have decided to approach Integrated Reporting must follow certain steps, the first of which is to create an IR team, 
made up of managers from all areas of the company. Our study has also investigated the difficulties encountered and the benefits perceived by the companies that faced the long process that integrated reporting requires. For the Italian companies studied, the primary motivation for adopting IR that can be extrapolated from the analysis of the results is to simplify and integrate the information regarding the company's business, in an effort to communicate in a complete and transparent way its capacity to create value in the present and in the future. Therefore, the analysis confirms that this new era of reporting will be characterized by the adoption of IR, supported and accompanied by integrated thinking. This shift in reporting style has now become essential for any organization that wants to prove to its stakeholders that it is, indeed, transparent, innovative, reliable, and able to represent its ability to create value with all of the material and non-material resources available. Regarding the difficulties companies have faced or are facing, $80 \%$ of the sample cite the struggle to fully understand the relationships and links between financial and non-financial performance as representing the biggest hurdle, by far; they recognize that it will be overcome only after the implementation, thanks to integrated thinking, of Integrated Reporting across all sectors of the company. One limitation of this research study is the inability to measure results. For example, the benefits listed are based on the perceptions of top managers but these perceptions are not measurable. The most evident limitation of this study concerns the sample described above, in paragraph four. The research could be expanded by providing the same survey to other European companies that prepare an IR, referring the study to a much broader number of cases. Nonetheless, at this time the findings of this research may help top management decision-makers to understand the process that led major Italian companies to take the approach of Integrated Reporting, so as to decide whether to start this practice themselves. Also, already knowing what the benefits that might result from the adoption of the IR are, company managers could be more willing to adopt this new reporting tool. We contribute to the extant IR literature by responding to several calls for research on internal IR implementation (see Steyn, 2014; De Villiers et al., 2014; Perego, Kennedy \& Whiteman, 2016). By showing the reasons cited by Italian companies that have started the process of IR, and expanding the benefits framework, the enriched literature will more fully show the increasingly widespread use of this new tool for reporting business performance and what it really means for companies.

\section{References}

The Association of Chartered Certified Accountants (ACCA). (2017). Insights into Integrated Reporting. London.

Accounting for sustainability and Global Reporting Initiative. (2012). The value of extrafinancial disclosure What investors and analysts said.

Abeysekera, I. (2013). A template for integrated reporting. Journal of Intellectual Capital, 14(2), 227-245. https://doi:10.1108/14691931311323869.

Adams, C. A. (2014). The International Integrated Reporting Council: A call to action. Critical Perspectives on Accounting, 27, 23-28. https://doi:10.1016/j.cpa.2014.07.001.

Black, S. (2012). Understanding transformation: Building the business case for integrated reporting. London: International Integrated Reporting Council.

Blesener, S. (2014). Realizing the benefits: The impact of integrated reporting. London: International Integrated Reporting Council.

Busco, C., Frigo, M. L., Quattrone, P., \& Riccaboni, A. (2013a). Integrated Reporting. Concepts and cases that Redefine Corporate Accountability. Springer, London.

Chartered Institute of Management Accountants (CIMA). (2015). Integrated reporting in the Public Sector. Retrieved from https://integratedreporting.org/wp-content/uploads/2016/09/IR-in-the-Public-Sector-CIMACGMA.pdf

Cheng M., Green W., Conradie P., Konishi N., \& Romi A. (2014). The International Integrated Reporting framework: key isuues and future research opportunities. Journal of International Financial Management \& Accounting, 25(1), 90-119.

Churet, C., \& Eccles, R. G. (2014). Integrated reporting, quality of management and financial performance. Journal of Applied Corporate Finance, 26(1), 56-64.

De Villiers C., Rinaldi L., \& Unerman J. (2014). Integrated Reporting: insights, gaps and an agenda for future research. Accounting, Auditing and Accountability Journal, 27(7), 1042-1067. https://dx.doi.org/10.1108/AAAJ-06-2014-1736

Eccles, R. G., \& Krzus, M. P. (2010). One Report. Integrated Reporting for a Sustainable Strategy, John Wiley \& 
Sons, Inc., Hoboken, New Jersey. Retrieved from https://ssrn.com/abstract=2388716

Eccles, R. G., \& Serafeim, G. (2015). Corporate and Integrated Reporting: a functional perspective, chapter in Stewardship of the future, edito da Ed Lawler, Sue Mohrman, James O’Toole, Greenleaf.

Ernst \& Young. (2015). La rendicontazione di sostenibilità: scenari e linee guida di riferimento.

Hampton, R. (2012). Brace yourself: more regulatory changes, Accountancy SA, 22-23.

Havlová, K. (2015). What integrated reporting changed: The case study of early. Procedia Economics and Finance, 34, 231-237, https://dx.doi.org/10.1016/S2212-5671(15)01624-X

International Integrated Reporting Council (IIRC). (2013b). The International Framework, IIRC, London.

King M., \& Roberts, L. (2013). Integrated: doing business in the 21 st century, Juta and company Ltd, Cape Town.

Kaplan, R. S. (1986). The role for empirical research in management accounting. Accounting, Organizations and Society, 11(4), 429-452.

Kreiner, K., \& Mouritsen, J. (2005). The analytical interview: relevance beyond reflexivity. In Tengblad, S., Solli, R. and Czarniawska, B. (Eds), The art of science, Liber \& Copenhagen Business School Press, Kristianstad, $S W($ pp. 153-176).

Krzus, M. P. (2011). Integrated Reporting: if not now, when? IRZ-Zeitschrift für International Rechnungslegung, $6,271-276$.

Lillis, A. M., \&Mundy, J. (2005). Cross-Sectional Field Studies in Management Accounting Research - Closing the Gaps between Surveys and Case Studies. Journal of Management Accounting Research, 17(1), 119-141.

Mohammad, E. H. (2017). Why company adopt Integrated Reporting? International Journal of Economics and Financial Issues, 7(1), 241-248. Retrieved from https: //www.econhournals.com

Morros, J. (2016). The integrated reporting: A presentation of the current state of art and aspects of integrated reporting that need further development. Intangible Capital, 12(1), 336-356. https://dx.doi.org/doi.org/10.3926/ic.700

Neely, A. (1999). The performance management revolution: why now and what next ? International Journal of $\begin{array}{llll}\text { Operations and Production } & \text { Management, }\end{array}$ https://dx.doi.org/10.1108/01443579910247437

Perego P., Kennedy, S., \& Whiteman, G. (2016). A lot of icing but little cake? Taking integrated reporting forward. Journal of Cleaner Production, 136, 53-64. https://dx.doi.org/10.1016/j.jclepro.2016.01.106

Qu, S. Q., \& Dumay, J. (2011). The qualitative research interview. Qualitative Research in Accounting \& Management, 8(3), 238-264.

Roslender, R., \& Hart, S. J. (2003). In search of strategic management accounting: theoretical and field study perspectives. Management Accounting Research, 14(3), 255-279.

South Africa Institute of Chartered Accountants (SAICA). (2015). Integrated Thinking. An exploratory survey. SAICA. Retrieved from https://integratedreporting.org.

Steyn, M. (2014). Organisational benefits and implementation challenges of mandatory integrated reporting. Sustainability Accounting, Management and Policy Journal, 5(4), 476-503. https://dx.doi.org/10.1108/SAMPJ-11-2013-0052

Stubbs, W., \& Higgins, C. (2014). Integrated Reporting and internal mechanisms of change. Accounting, Auditing and Accountability Journal, 27(7), 1068-1089. https://doi.org/10.1108/AAAJ-03-2013-1279

Thomson, I. (2015). But does sustainability need capitalism or an integrated report? A commentary on "The International Integrated Reporting Council: A story of failure. Critical Perspectives on Accounting, 27, 18-22. https://dx.doi.org/10.1016/j.cpa.2014.07.003 1045-2354

Van, B. K. (2014). Towards a legitimate compromise? An exploration of Integrated Reporting in the Netherlands. $\begin{array}{llll}\text { Accounting, Auditing and } & \text { 1157-1189. }\end{array}$ https://doi:10.1108/AAAJ-04-2013-1309.

Vergnano, F. (2010). Intervista di Franco Vergnano a Robert Eccles - Aziende verso One Report. L'Impresa, n. 12.

Wengraf, T. (2001). Qualitative research interviewing: Biographic narrative and semi-structured methods, Sage. 
White L. A. (2005). New Wine, New Bottles: The Rise of Non - Financial Reporting. A Business Brief by Business for Social Responsibility. Retrieved from https://www.bsr.org

Yongvanich, K., \& Guthrie, J. (2006). An Extended Performance Reporting Framework. Business Strategy and the Environment, 15, 309-321.

\section{Copyrights}

Copyright for this article is retained by the author(s), with first publication rights granted to the journal.

This is an open-access article distributed under the terms and conditions of the Creative Commons Attribution license (http://creativecommons.org/licenses/by/4.0/). 